\title{
The role of telomere-binding modulators in pluripotent stem cells
}

\author{
Feng $\mathrm{Li}^{1}{ }^{\mathbb{D}}$, Yuanlong $\mathrm{Ge}^{1} \mathbb{D}$, Dan $\mathrm{Liu}^{2}$, Zhou Songyang ${ }^{1,2 \bowtie}$ \\ ${ }^{1}$ State Key Laboratory of Oncology in South China, Cancer Center, Collaborative Innovation Center for Cancer Medicine, and \\ Key Laboratory of Gene Engineering of the Ministry of Education, School of Life Sciences, Sun Yat-sen University, \\ Guangzhou 510275, China \\ 2 Verna and Marrs Department of Biochemistry and Molecular Biology, Baylor College of Medicine, One Baylor Plaza, Houston, \\ TX 77030, USA \\ $\triangle$ Correspondence: songyang@bcm.edu (Z. Songyang)
}

Received April 2, 2019 Accepted May 7, 2019

\begin{abstract}
Pluripotent stem cells (PSCs) such as embryonic stem cells (ESCs), ESCs derived by somatic cell nuclear transfer (ntESCs), and induced pluripotent stem cells (iPSCs) have unlimited capacity for self-renewal and pluripotency and can give rise to all types of somatic cells. In order to maintain their self-renewal and pluripotency, PSCs need to preserve their telomere length and homeostasis. In recent years, increasing studies have shown that telomere reprogramming is essential for stem cell pluripotency maintenance and its induced pluripotency process. Telomere-associated proteins are not only required for telomere maintenance in both stem cells, their extra-telomeric functions have also been found to be critical as well. Here, we will discuss how telomeres and telomere-associated factors participate and regulate the maintenance of stem cell pluripotency.
\end{abstract}

KEYWORDS telomere, pluripotent stem cells, telomerase, $\mathrm{ALT}$, shelterin/telosome complex

\section{TELOMERES}

Telomeres are ends of linear chromosomes that are bound by a host of protein factors and form a complex nucleoprotein structure. In mammalian cells, telomeres are consisted of repetitive [TTAGGG]n sequences and protected by the core six-protein shelterin/telosome complex (Xin et al., 2008; de Lange, 2018). The shelterin/telosome complex in turn recruits many other factors from diverse cellular pathways to telomeres for protection and maintenance. The telomeric
DNA adopts the protective T-loop structure where the singlestranded $3^{\prime}$ overhang invades into the double-stranded telomeric region (Griffith et al., 1999; Doksani et al., 2013), and thus protected from nucleolytic degradation and activation of the DNA damage response. Due to the end replication problem, telomeres undergo gradual shortening during proliferation in normal somatic cells. Telomere attrition during successive cell divisions can ultimately lead to chromosomal instability and contribute significantly to genomic rearrangements that can result in tumorigenesis.

\section{TELOMERES IN PSCS}

Pluripotent stem cells (PSCs), including embryonic stem cells (ESCs), nuclear transfer ESCs (ntESCs) and induced pluripotent stem cells (iPSCs), have the potential of unlimited-proliferation and the capacity to differentiate into any cell type. Therefore, PSCs can be used for any cell type replacement and have great value for regenerative medical. Proper regulation of telomere length and telomere-binding proteins is critical for telomere function and genomic stability, both in somatic cells and PSCs. Mouse ESCs and/or iPSCs with short telomeres exhibited unsuccessful teratoma formation and chimera production and failed to produce ES/iPS mice (Huang et al., 2011). It has been reported that reprogramming by retroviral transduction of iPS factors of mouse primary embryonic fibroblasts also resulted in a dramatic increase in telomere length, similar to what was observed in ES cells (Marion et al., 2009). Furthermore, telomeres were also elongated during reprogramming of human blastocysts to embryonic stem cells and reached a relatively stable level in these iPSCs (Zeng et al., 2014). Cells with longer telomeres may have higher pluripotency potential and be 
positively selected from a heterogeneous population. Singlecell telomere length analysis coupled with RNA sequencing (scT\&R-seq) revealed that hESCs with short telomeres exhibited more characteristics associated with differentiated lineages, whereas those with longer telomeres better maintained pluripotency (Wang et al., 2017). Telomere length also plays an important role in stem cell differentiation. iPSCs with relatively long telomeres were found to differentiate more to the mesoderm and endoderm lineages, such as cardiac progenitor cells (Aguado et al., 2017). In summary, telomere length may help determine the pluripotency status of stem cells (Fig. 1).

How the state of telomere affects stem cell pluripotency is an essential question. Previous studies have shown that the telomeric chromatin appears more open in PSCs than in somatic cells, and becomes more repressive during differentiation (Marion et al., 2009; Wong et al., 2009). Conversely, the reprogramming of adult somatic cells into pluripotent stem cells can "switch" the telomeric chromatin from a repressive state to more open and stem cell-like. Although how such telomeric chromatin changes affect stem cell pluripotency remains unknown, it is clear that telomeric chromatin dynamics has a fundamental role in ensuring stem cell pluripotency.

\section{TELOMERE MAINTENANCE IN PSCS}

One of the hallmarks of stem cells is the presence of unlimited growth potential, which is enabled by a telomere maintenance mechanism (TMM) capable of completely counteracting normal telomere shortening. PSCs can proliferate indefinitely while maintaining pluripotency and avoid telomere attrition and genome instability by elongating and protecting their telomeres. Short telomeres in ESCs lead to reduced pluripotency and unstable differentiation (Pucci et al., 2013). As is the case for somatic cells, two mechanisms exist to ensure telomere lengthening in ESCs, elevating telomerase activity and alternative lengthening of telomeres (ALT) (Liu et al., 2007). Losing telomerase activity in ES/iPS cells was shown to result in critically shortened telomeres (Huang et al., 2011; Pucci et al., 2013), supporting a major role for telomerase in telomere maintenance in PSCs.

The telomerase holoenzyme adds telomeric DNA repeats to the ends of chromosomes (Greider and Blackburn, 1989; Lingner et al., 1997). It is a specialized ribonucleoprotein complex, composed of the reverse transcriptase TERT and the RNA template TERC as well as associating proteins such as the ribonucleoprotein dyskerin DKC1 (Cohen et al., 2007). Unlike normal somatic cells, telomerase is usually activated and expressed in stem and cancer cells. Telomerase-dependent telomere maintenance is required for pluripotency and long-term self-renewal of human and mouse PSCs (Huang et al., 2011; Huang et al., 2014; Liu, 2017).

Despite the major role telomerase plays in ESC establishment and iPSC generation, mouse $\mathrm{TERC}^{-/-}$and $\mathrm{TERT}^{-/-}$ ESCs survivor lines were found to maintain their telomere length using the telomerase-independent mechanism ALT (Niida et al., 2000; Wang et al., 2005). The ALT pathway has been found in $\sim 10 \%-15 \%$ cancers and is usually characterized by the presence of ALT-associated promyelocytic leukemia (PML) bodies (APBs), extrachromosomal telomeric repeats (ECTR), and high frequency of telomere sister chromatid exchange (T-SCE) in cells (Cesare and Reddel, 2010). Interestingly, mESCs and early cleavage stage embryos might have elongated their telomeres using an ALTlike mechanism, displaying rapid telomere elongation along with increased T-SCE (Liu et al., 2007; Zalzman et al., 2010). Telomere maintenance by telomerase and the ALT pathway may coexist in human cells under certain circumstances in cancer cells (Cerone et al., 2001), and in ESCs and iPSCs, as was reported in studies that found telomerase reactivation as well as ALT characteristics in these cells (Wang et al., 2012; Chang et al., 2013). More work is required for a true
Figure 1. Telomere length and pluripotency. Due to the end replication problem, telomere shortening occurs in stem cell differentiation and aging. Through telomerase and the ALT mechanism, telomeres are elongated to sustain self-renewal.

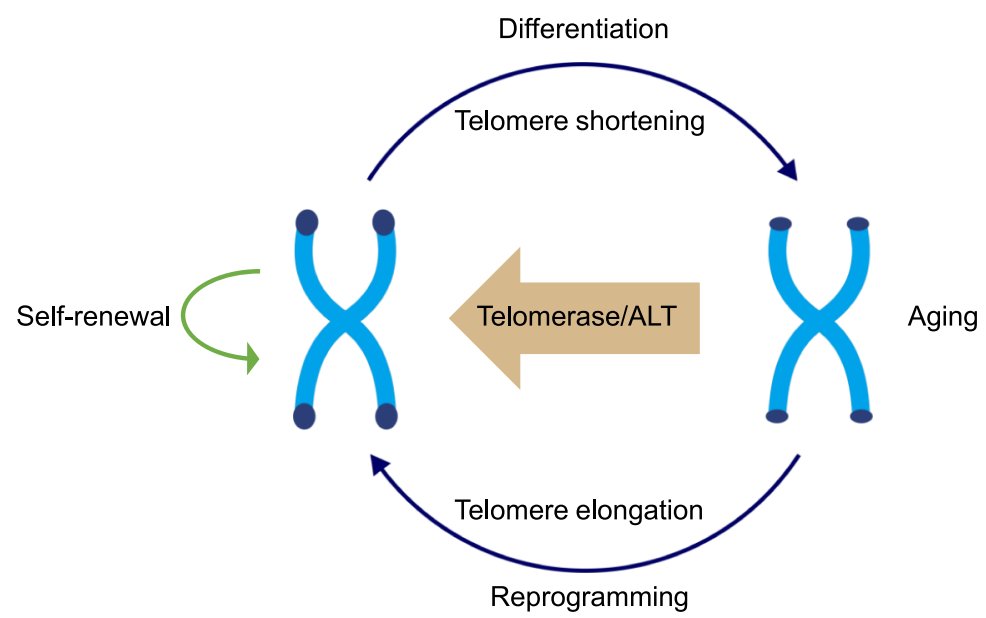


understanding of the mechanisms of ALT pathway activation and utilization in pluripotency maintenance.

\section{TELOMERASE IN PSCS}

Although the telomerase itself is dispensable for establishing ESC or iPSC lines (Marion et al., 2009; Huang et al., 2011; Wang et al., 2012), telomerase-deficient mice are viable for only six generations (Huang et al., 2014). TERC $^{-/-}$mESCs with short telomeres showed genome-wide DNA hypomethylation and altered H3K27me3 modification, which led to unstable ESC differentiation in vitro (Pucci et al., 2013). TERT knockout hESCs showed progressive telomere shortening, which resulted in apoptosis and/or limited proliferation (Liu et al., 2016). Further, TERC $^{+/-} \mathrm{mESCs}$ had a significantly reduced ability to generate ESC mice compared with wild-type mESCs (Huang et al., 2011). And late-generation TERC $^{-/-}$mice often exhibit striking phenotypes associated with telomere dysfunction, including chromosomal abnormalities, development defects, aging and tumor formation (Blasco et al., 1997; Herrera et al., 1999; Rudolph et al., 1999). Conversely, telomerase reactivation by TERT overexpression could reverse tissue degeneration in aged telomerase-deficient mice (Jaskelioff et al., 2011). Upregulation of hTERT and increased telomerase activity also improved the proliferative and colony-forming ability of hESCs by modulating the cell cycle dynamics (Yang et al., 2008). TERT-overexpressing hESCs displayed advantages in growth potential and stress resistance, and enhanced differentiation toward the hematopoietic lineage (Armstrong et al., 2005). Together, these findings provide a strong connection between telomerase status and stem cell pluripotency.

Given the importance of telomere maintenance in PSCs, the factors that can regulate telomerase expression, recruitment and activity are also expected to play a significant part in PSC biology. Several studies showed that pluripotency transcription regulators, also known as the four Yamanaka factors (OCT4, SOX2, KLF4 and C-MYC), could activate telomerase genes during reprogramming. For example, OCT3/4 and NANOG could bind to the TERC promoter and activate TERC transcription (Agarwal et al., 2010). Additionally, KLF4 was found to specifically and directly bind to the TERT proximal promoter and activate TERT expression in ESCs and iPSCs (Wong et al., 2010a; Hoffmeyer et al., 2012; Wang et al., 2012). KLF4 knockdown in human ESCs resulted in TERT expression downregulation and ESC differentiation, whereas TERT overexpression could rescue these phenotypes (Wong et al., 2010a). The factors that are required for telomerase RNA transcription and maturation should also play a central role in PSC maintenance. We recently found that TOE1 acts as a $3^{\prime}$ exonuclease for TERC/hTR processing and telomere maintenance (Deng et al., 2019). Future studies of TOE1 in PSCs will provide more understanding of the link between telomerase and pluripotency.

\section{TELOMERE HISTONES AND EPIGENETIC MODIFICTIONS IN PSCS}

Previous studies have pointed the fundamental roles of chromatin epigenetic status in stem cell pluripotency maintenance (Meshorer and Misteli, 2006; Santos et al., 2010; Pfaff et al., 2013; Kobayashi and Kikyo, 2015; Ikeda et al., 2017). The undifferentiated stem cells contain a more open and active chromatin state when compared to the differentiated somatic cells. The differentiation process is always accompanied by a global change in chromatin histone modifications, including changes in active (acetylated H3K9 and $\mathrm{H} 3 \mathrm{~K} 4 \mathrm{me} 3$ ) and repressive (H3K9me3 and $\mathrm{H} 3 \mathrm{~K} 27 \mathrm{me} 3$ ) chromatin markers. Nuclear reprogramming also involves a large-scale resetting of chromatin structure and epigenetic status, which leads to a more open chromatin state. Despite it has been shown that chromatin structure could impact telomere maintenance in cancer cells, little is known of how chromatin structure affects telomere maintenance in pluripotent stem cells. Previous works have reported that ES cells and iPS cells contain less repressive telomeric chromatin when compared with the differentiated cells (Marion et al., 2009; Wong et al., 2009). mouse iPS reprogramming by retrovial transduction of pluripotency fators also results in a dramatic increase in telomere length to level functionally equivalent to those in mouse ES cells (Marion et al., 2009). We hypothesize that the chromatin status at telomere or subtelomere may has a direct impact on the telomere length and pluripotency maintenance in ES cells.

Besides core histones, the conserved histone variant $\mathrm{H} 3.3$ is also found to be associated with active/open chromatin. H3.3 can localize to telomeres in mESCs and embryonic germ cells, but not in non-pluripotent cells (Wong et al., 2009). During ESC differentiation, H3.3 levels at telomeres appeared to decease, which was companied by an increase of H4K20me3 and H3K9me3, both of which are markers of repressive heterochromatin (Marion et al., 2009). It is possible that $\mathrm{H} 3.3$ loading may prevent trimethylation of H4K2O and H3K9 and promote telomere elongation in pluripotent cells. These findings propose that $\mathrm{H} 3.3$ plays a key role in controlling telomere chromatin status and confers the capacity to maintain telomere length in ES cells. The relatively open telomere chromatin becomes more accessible to regulators such as telomerase or factors that mediate homologous recombination, which can both facilitate telomere elongation.

$\mathrm{H} 3.3$ is deposited on telomeres and pericentric heterochromatin by the ATRX/DAXX chaperone complex (Lewis et al., 2010; Wong et al., 2010b) (Fig. 2). ATRX is a member of the SNF2 family of helicase/ATPases that contributes to chromatin remodeling and repression. It has been shown that ATRX plays a unique function in regulation of telomere chromatin integrity in pluripotent mouse embryonic stem cells, but not in differentiated cells (Wong et al., 2010b). ATRX interacts with $\mathrm{H} 3.3$ and is required for the recruitment of HP1 at telomeres in pluripotent stem cells (Wong et al., 


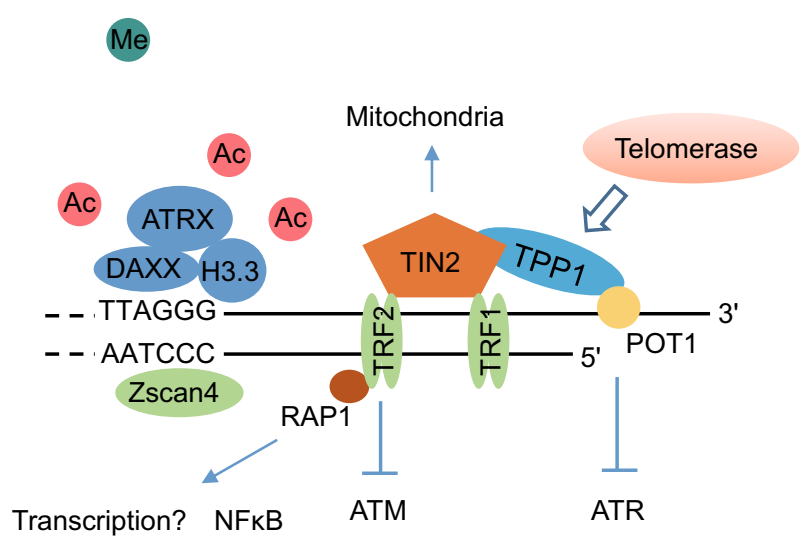

\begin{abstract}
Ac Histone acetylation Me Histone methylation
Figure 2. Organization and molecular functions of the telomere binding proteins and histone modifications at hPSC telomeres. Telomeric DNA is protected from DNA damage response by the shelterin/telosome proteins: the double-stranded telomeric DNA binding factors TRF1 and TRF2, the single-stranded telomeric DNA binding factor POT1, the organizing factors TIN2 and TPP1, and the TRF2-binding factor RAP1. Telomerase is recruited by the shelterin complex to elongate telomeres. Some extra-telomere roles of shelterin/ telosome proteins are also shown as indicated. hPSCs show more open telomeric chromatin status, including more histone acetylation and less histone methylation. ATRX, DAXX and H3.3 work as a complex to bind to telomere and regulate telomere epigenetic status in hPSCs. Zscan4 localizes to telomeres and promote telomere elongation and epigenetic regulation in hPSCs.
\end{abstract}

2010b). However, the level of ATRX at telomere is decreased during ES cell differentiation, suggesting an essential role of ATRX as a key regulator of telomere chromatin in pluripotency stem cells (Wong et al., 2010b). Moreover, ATRX and H3.3 colocalize with telomeric DNA at PML bodies, which serve as platforms for the maintenance of telomeric chromatin integrity in ESCs (Chang et al., 2013). These telomere-associated PML bodies (APBs) is associated with the pluripotent of mESCs, and is gradually reduced during ESC differentiation. Future studies are needed to define the functional link between ATRX and novel pathways involved in the regulation of telomeric chromatin status, telomere length homeostasis and pluripotency maintenance.

PSCs can tolerate global DNA hypomethylation. Our recent study showed that genome-wide demethylation promotes co-enrichment of DAXX and ATRX at tandem repetitive elements, including telomeres and subtelomeres, in mESCs and during early embryogenesis(He et al., 2015). The DAXX/ATRX complex is required for transcriptional repression and protection of repetitive elements in mESCs during DNA demethylation(He et al., 2015). Loss of DAXX or
ATRX resulted in an increased IAP transcription in DNMT knockout cells. In addition, depletion of DAXX or ATRX in DNMT knockout cells, but not wild-type mES cells, exhibited increased fragile telomeres and dysregulated telomere length control. We also found that DAXX played a central role for DAXX/ATRX complex recruitment to telomere/subtelomere regions, and might involve in SUV39H1 recruitment and $\mathrm{H} 3 \mathrm{~K} 9$ trimethylation (He et al., 2015). Thus, the DAXX/ ATRX complex is essential for repetitive sequences repression and protection in response to global DNA hypomethylation in mESCs and during early embryogenesis. Further investigation of the regulation of DAXX and ATRX during embryogenesis and ES cell differentiation should shed light on the mechanisms of pluripotency maintenance and embryo development.

\section{Zscan4 IN PSCS}

Zscan4 is specifically expressed in late 2-cell stage embryos and ESCs, and inactivated following ESC differentiation (Falco et al., 2007). It was found that Zscan4 could target to telomeres and promote telomere elongation by homologous recombination (HR) in ESCs (Zalzman et al., 2010) (Fig. 2). During early embryonic development, T-SCE and HR are required for telomere elongation (Liu et al., 2007). Perhaps Zscan4 promotes HR-mediated lengthening of telomeres in early embryos. However, the exact mechanisms underlying Zscan4-mediated recombination regulation remain to be determined. Zscan4 has also been found to contribute to telomere elongation and reprogramming during SCNT and iPSC generation, although Zscan4 overexpression was only required for the first few days of iPSC formation (Hirata et al., 2012). Further studies have demonstrated a role of Zscan4 in protecting genome stability during reprogramming and improving the quality of iPSCs (Jiang et al., 2013). Previous studies showed that epigenetic status might play a critical role in Zscan4 regulation. Histone hyperacetylation activates Zscan4 expression, whereas histone hypoacetylation represses (Dan et al., 2015). DNA hypermethylation induced by Tet1/2 double-knockout (DKO) or Tet1/2/3 triple-knockout (TKO) upregulates Zscan4, which may compensate for telomere shortening ( $\mathrm{Lu}$ et al., 2014). In addition, TBX3, a pluripotency maker required for self-renewal of ESCs and iPSCs (Han et al., 2010; Lu et al., 2011), activates Zscan4 gene expression and elongates telomeres in mESCs via indirect effects on DNA methylation (Dan et al., 2013). Again, more work is needed (e.g., single-cell sequencing) to understand how Zscan4 is regulated during stem cell differentiation and embryo development.

\section{THE SHELTERIN/TELOSOME COMPLEX IN PSCS}

The six-subunit shelterin/telosome complex comprises of three DNA-binding proteins (TRF1, TRF2, and POT1) and three proteins with no demonstrable DNA-binding activities (TPP1, TIN2, and RAP1) (Xin et al., 2008; de Lange, 2018) 
(Fig. 2). These six core telomere-associated proteins regulate telomerase access to telomeres, protect telomere ends from DNA damage response, and ensure proper telomere maintenance by recruiting other factors (Xin et al., 2007; Abreu et al., 2010; Nandakumar et al., 2012; Sexton et al., 2012; Zhong et al., 2012). Through the concerted efforts of telomerase and telomere-binding proteins, cells are able to counteract the end replication problem in both somatic cells and PSCs. Further, extra-telomeric functions of shelterin/ telosome proteins in pluripotency maintenance have also begun to be appreciated.

\section{TRF1}

The telomere repeat factor 1 or TRF1 binds to the doublestranded region of telomeres (Court et al., 2005). TRF1 was found to control telomere length negatively and promote telomere replication (van Steensel and de Lange, 1997; Sfeir et al., 2009). During in vitro derivation of ES-cell lines from the inner cell mass (ICM), increased TRF1 expression was observed before the onset of telomere elongation (Varela et al., 2011). Highly upregulated expression of TRF1 was also found in ESCs and iPSCs, independent of of the length status of telomeres (Boue et al., 2010; Schneider et al., 2013; Marion et al., 2017). These findings suggest that TRF1 may serve as a pluripotency marker. Moreover, TRF1 is necessary for both induction and maintenance of pluripotency. Knocking out TRF1 reduced in vivo reprogramming efficiency. Interestingly, TRF1 is also a direct transcriptional target of Oct3/4 (Schneider et al., 2013). It suggests that high level of TRF1 in stem cells is conducive to telomere replication and genome stability.

\section{TRF2}

Like TRF1, the telomere repeat factor 2 or TRF2 also binds to double-stranded telomere DNA (Bilaud et al., 1997) . TRF2-binding is thought to facilitate T-loop formation (Stansel et al., 2001). TRF2 has been shown to suppress ATM signaling activation and prevent non-homologous end joining (NHEJ) and homology-directed repair (HDR) at telomeres (Celli et al., 2006; Bae and Baumann, 2007; Denchi and de Lange, 2007) (Fig. 2). Loss of TRF2 can lead to telomere uncapping and activation of DNA damage response at telomeres (van Steensel et al., 1998; Kim et al., 2017). Interestingly, TRF2 deletion in alveolar stem cells was found to limit their self-renewal and differentiation (Alder et al., 2015). In comparison, TRF2-overexpresion in mouse induces epidermal stem cells dysfunction with critically short telomeres. Meanwhile, p53 deletion could rescues severe phenotypes in TRF2-overexpression mice, suggesting that DNA damage response involve in epidermal stem cells dysfunction (Stout and Blasco, 2009). Notably, TRF2 also poses an essential role in controlling neural stem cell fate, which is independent of telomere function. It has been reported that TRF2 is required for embryonic and adult neurogenesis (Ovando-Roche et al., 2014; Lobanova et al., 2017), but dosen't play a role in terminally differentiated neurons. TRF-S, one splicing type of TRF2 in neural stem cells, prefer to bind mRNA but not telomeric DNA. The findings suggest a pivotal role for TRF2-S in axonal mRNA localization that enhances axon outgrowth and neurotransmitter release (Zhang et al., 2008; Zhang et al., 2015a; Grammatikakis et al., 2016). Beyond All That, TRF2 could be found at genomic DNA to regulate genes transcription and heterochromatin maintenance (El Mai et al., 2014; MendezBermudez et al., 2018). Partial deletion of TRF2 increases the radiosensitivity of human mesenchymal stem cells (Orun et al., 2016; Serakinci et al., 2018). In all, TRF2 plays essential roles in stem cell state controlling, and it may have extra-telomere functions in this regulation. However, the functions of TRF2 independent of telomere are not clear in pluripotent stem cells, and more studies are needed to indicate its possible role in pluripotency maintenance.

\section{TPP1 and POT1}

Of the six core telomere proteins, only POT1 has the ability to specifically bind the G-rich single-stranded telomere overhang (Baumann and Cech, 2001). It is required for suppressing ATR-mediated DNA damage response (Churikov et al., 2006; Denchi and de Lange, 2007) (Fig. 2). Most vertebrates, including humans, possess a single POT1 gene. But there are two POT1 genes (POT1a and POT1b) in rodent (Hockemeyer et al., 2006). Knockdown POT1a or knockout POT1b in mice result in increased telomeric DNA damage, and lead to apoptosis of hematopoietic stem cells (Wang et al., 2011; Hosokawa et al., 2017). TPP1 was identified as interacting protein of POT1 in three independent research group (Houghtaling et al., 2004; Liu et al., 2004b; Ye et al., 2004b). The mutation of TPP1 would lead to adrenocortical dysplasia, which is a disease with developmental defects in organs derived from the urogenital ridge (Keegan et al., 2005). TPP1 functions as a molecular minihub at the end of telomeres, by interacting with POT1, TIN2, and TERT (O'Connor et al., 2006; Xin et al., 2007). The TPP1-POT1 heterodimer functions analogously to ciliate TEBP to facilitate telomerase recruitment, while TPP1-TIN2 interaction helps bridge the double- and single-stranded DNA binding activities of the shelterin/telosome (Wang et al., 2007; Xin et al., 2007). TPP1 depletion in cancer cells caused DNA damage response at telomeres and led to telomere dysfunction (Guo et al., 2007; Xin et al., 2007). Knockdown SIRT1 reduce TPP1 expression in young mesenchymal stem cells (MSCs), leading telomeric DNA damage and cell senescence (Chen et al., 2014). TEL patch mutation of TPP1 suppresses telomerase recruitment and induce cell cycle arrest or apoptosis in certain cancer cells (Nakashima et al., 2013). Indeed, abrogation of TPP1 also abolished telomere elongation in human embryonic stem cells and mouse embryonic fibroblast (MEF) reprogramming, 
supporting a role of TPP1 in maintenance of PSCs (Tejera et al., 2010; Sexton et al., 2014).

\section{TIN2}

TIN2 (TRF1-interacting nuclear factor 2) was initially discovered as a protein that could interact with TRF1 (Kim et al., 1999). It has since been shown to function as a central component of the shelterin/telosome complex. TIN2 can interact with both TRF1 and TRF2 on the one hand, and TPP1 on the other, thereby bringing together the double- and single-stranded DNA-binding activities within the complex for telomere maintenance (Kim et al., 1999; Liu et al., 2004a; Ye et al., 2004a; O'Connor et al., 2006; Chen et al., 2008; Kim et al., 2009; Takai et al., 2011). The interaction between TIN2 and TPP1 also important for telomerase recruitment to telomere (Abreu et al., 2010; Yang et al., 2011). Knocking out (KO) TIN2 in mice is embryonically lethal and CRISPR-mediated TIN2 KO in human cells also led to cell death (Chiang et al., 2004; Kim et al., 2017). These observations support extra-telomeric functions of TIN2. Indeed, TIN2 has been shown to also localize to the mitochondria and regulates oxidative phosphorylation (Chen et al., 2012). Additionally, mutations of TIN2 have been identified in patients with dyskeratosis congenita (DC), a syndrome characterized by bone marrow failure and somatic stem cell dysfunction in multiple organs, such as the epidermis and the hematopoietic system. More work is needed to understand the molecular and cellular consequences of TIN2 mutations to pluripotent stem cells.

\section{RAP1}

Repressor/activator protein 1 or RAP1 localizes to telomere via its interaction with TRF2 ( $\mathrm{Li}$ et al., 2000; Chen et al., 2011). The RAP1-TRF2 heterodimer protects telomeres from inappropriate HDR and NHEJ activation (Bae and Baumann, 2007; Sfeir et al., 2010; Rai et al., 2016). RAP1 deficiency can result in telomere shortening in human cells (O'Connor et al., 2004). While RAP1 $\mathrm{KO}$ in mice did not lead to embryonic lethality, in addition to shortened telomeres, hyperpigmentation and increased DNA damage activation could also be observed in adult RAP1 KO mice (Martinez et al., 2010). Mammalian Rap1 associates with DNA through its interaction with TRF2, including telomere and extratelomere. Extra-telomeric RAP1-binding sites have been found in the vicinity of genes, suggesting a role for RAP1 in transcriptional control (Martinez et al., 2010; Yang et al., 2011; Martinez et al., 2013). Not all RAP1 proteins are in the nucleus. Cytoplasmic Rap1 is an inhibitor kinase (IKK) adaptor that controls NFKB pathway (Teo et al., 2010). Suppression of NFKB pathway through knockdown RAP1 is benefit for atherosclerotic lesions and myocardial infarction (Cai et al., 2015; Zhang et al., 2015b). To further investigate the telomeric and extra-telomeric functions of RAP1 should help shed more light on its possible role in pluripotency maintenance.

\section{CONCLUSIONS AND PERSPECTIVES}

Multiple links have been established between telomere homeostasis and stem cell pluripotency maintenance. Sufficient telomere length is critical for unlimited self-renewal of PSCs. Telomere length and integrity may serve as general signatures to evaluate the quantity of ESCs and iPSCs. Longer telomeres would be advantageous for human ESCs and iPSCs in the application of PSCs in regenerative medicine. However, excessive telomere elongation heightens sensitivity of hESCs to replication stress at overly long telomeres, and causes the formation of C-circles (Rivera et al., 2017). Thus, the tight control of telomere length homeostasis is essential for stem cell status maintenance. In addition, insight into telomere length regulation in PSCs may have implications in understanding aging and tumorigenesis and lead to discoveries of novel anti-cancer treatment.

Telomere length maintenance in ESCs and iPSCs is regulated by telomere-binding modulators and epigenetic modifications. Additionally, higher level of the shelterin/telosome component TRF1 also correlates with higher pluripotency of stem cells. Numerous studies have elucidated the roles of these telomere-binding proteins in telomere homeostasis. In the future, more focused effort should be made to delineate how stem cell pluripotency is regulated by telomere-binding modulators. Epigenetic changes at telomeres are acquired during reprogramming and ESC differentiation, these epigenetic modifications may provide a more flexible and efficient system to control of telomere length regulation in pluripotent cells. Future studies into how these telomeric chromatin status is regulated and contributes to the telomere homeostasis would provide insights to understand the mechanism of pluripotency maintenance and aging.

Mutations in telomere proteins have been identified in many human diseases including DC. Our previous systematic analysis of human shelterin/telosome knockout cells has revealed functional differences between human and mouse telomeric proteins in telomere length homeostasis and endprotection (Kim et al., 2017). In addition, extra-telomere functions of telomere proteins highlight an essential link between telomeres and stem cell pluripotency. Higher level of TRF1 correlates with higher pluripotency of stem cells. TRF2-RAP1 could be found at genomic DNA to regulate genes transcription and heterochromatin maintenance. TIN2 has been shown to localize to the mitochondria and regulate oxidative phosphorylation. The extra-telomere functions of shelterin/telosome components will be found in pluripotency maintenance. In vivo studies will be necessary to fully understand the molecular functions of telomere-binding proteins in somatic stem cells and tissue development.

The role of telomere binding proteins in the stem cell selfrenewal and pluripotency maintenance has been well discussed. However, the functions of these binding proteins in 
stem cell differentiation are still rarely studied. During the differentiation process, the gradually shorter telomeres may release some of the telomere binding proteins from telomeres or recruit some new factors to telomeres, which may affect the process of differentiation. Future studies should focus on the specific role of these telomere binding modulators in stem cell differentiation. In addition, telomere shortening or uncapping in stem cells leads to cell senescence and aging. However, previous studies usually focus on cellular level, but rarely mention individual level. What are the differences of telomere binding proteins in stem cells between young and elder individuals? How these differences contribute to individual stem cell therapy? Further studies are needed.

\section{ACKNOWLEDGEMENTS}

This study was supported by National Natural Science Foundation of China (Grant Nos. 81871109, 31401223, 81330055, 31570827, 91749113, 91640119 and 31871479); National Key Research and Development Program of China (2017YFA0102801, 2018YFA010 7003); Natural Science Foundation of Guangdong Province (2017A030313116).

\section{ABBREVIATIONS}

$A L T$, alternative lengthening of telomeres; APBs, telomere-associated PML bodies; DC, dyskeratosis congenita; DKO, Tet1 and Tet2 double-knockout; ECTR, extrachromosomal telomeric repeats; ESCs, embryonic stem cells; HAT, histone acetyltransferase; HDAC, histone deacetylase; HDR, homology directed repair; HR, homologous recombination; HSC, hematopoietic stem cell; ICM, inner cell mass; iPSCs, induced pluripotent stem cells; MEF, mouse embryonic fibroblast; NHEJ, non-homologous end joining; ntESCs, nuclear transfer ESCs; PSCs, pluripotent stem cells; TKO, Tet1/2/3 tripleknockout; TMM, telomere maintenance mechanism; T-SCE, telomere sister chromatid exchange

\section{COMPLIANCE WITH ETHICS GUIDELINES}

Feng Li, Yuanlong Ge, Dan Liu and Zhou Songyang declare that they have no conflict of interest.

This article does not contain any studies with human or animal subjects performed by the any of the authors.

\section{OPEN ACCESS}

This article is distributed under the terms of the Creative Commons Attribution 4.0 International License (http://creativecommons.org/ licenses/by/4.0/), which permits unrestricted use, distribution, and reproduction in any medium, provided you give appropriate credit to the original author(s) and the source, provide a link to the Creative Commons license, and indicate if changes were made.

\section{REFERENCES}

Abreu E, Aritonovska E, Reichenbach P, Cristofari G, Culp B, Terns RM, Lingner J, Terns MP (2010) TIN2-tethered TPP1 recruits human telomerase to telomeres in vivo. Mol Cell Biol 30:29712982

Agarwal S, Loh YH, McLoughlin EM, Huang J, Park IH, Miller JD, Huo H, Okuka M, Dos Reis RM, Loewer S et al (2010) Telomere elongation in induced pluripotent stem cells from dyskeratosis congenita patients. Nature 464:292-296

Aguado T, Gutierrez FJ, Aix E, Schneider RP, Giovinazzo G, Blasco MA, Flores I (2017) Telomere length defines the cardiomyocyte differentiation potency of mouse induced pluripotent stem cells. Stem Cells 35:362-373

Alder JK, Barkauskas CE, Limjunyawong N, Stanley SE, Kembou F, Tuder RM, Hogan BL, Mitzner W, Armanios M (2015) Telomere dysfunction causes alveolar stem cell failure. Proc Natl Acad Sci USA 112:5099-5104

Armstrong L, Saretzki G, Peters H, Wappler I, Evans J, Hole N, von Zglinicki T, Lako M (2005) Overexpression of telomerase confers growth advantage, stress resistance, and enhanced differentiation of ESCs toward the hematopoietic lineage. Stem Cells 23:516-529

Bae NS, Baumann P (2007) A RAP1/TRF2 complex inhibits nonhomologous end-joining at human telomeric DNA ends. Mol Cell 26:323-334

Baumann P, Cech TR (2001) Pot1, the putative telomere endbinding protein in fission yeast and humans. Science 292:11711175

Bilaud T, Brun C, Ancelin K, Koering CE, Laroche T, Gilson E (1997) Telomeric localization of TRF2, a novel human telobox protein. Nature Genetics 17:236-239

Blasco MA, Lee HW, Hande MP, Samper E, Lansdorp PM, DePinho RA, Greider CW (1997) Telomere shortening and tumor formation by mouse cells lacking telomerase RNA. Cell 91:25-34

Boue, S., Paramonov, I., Barrero, M.J., and Izpisua Belmonte, J.C. (2010). Analysis of human and mouse reprogramming of somatic cells to induced pluripotent stem cells. What is in the plate? PLoS ONE 5.

Cai Y, Sukhova GK, Wong HK, Xu A, Tergaonkar V, Vanhoutte PM, Tang EH (2015) Rap1 induces cytokine production in proinflammatory macrophages through NFkappaB signaling and is highly expressed in human atherosclerotic lesions. Cell Cycle (Georgetown, Tex) 14:3580-3592

Celli GB, Denchi EL, de Lange T (2006) Ku70 stimulates fusion of dysfunctional telomeres yet protects chromosome ends from homologous recombination. Nat Cell Biol 8:885-890

Cerone MA, Londono-Vallejo JA, Bacchetti S (2001) Telomere maintenance by telomerase and by recombination can coexist in human cells. Hum Mol Genet 10:1945-1952

Cesare AJ, Reddel RR (2010) Alternative lengthening of telomeres: models, mechanisms and implications. Nat Rev Genet 11:319330 
Chang FT, McGhie JD, Chan FL, Tang MC, Anderson MA, Mann JR, Andy Choo KH, Wong LH (2013) PML bodies provide an important platform for the maintenance of telomeric chromatin integrity in embryonic stem cells. Nucleic Acids Res 41:44474458

Chen Y, Yang Y, van Overbeek M, Donigian JR, Baciu P, de Lange T, Lei $\mathrm{M}$ (2008) A shared docking motif in TRF1 and TRF2 used for differential recruitment of telomeric proteins. Science 319:10921096

Chen Y, Rai R, Zhou ZR, Kanoh J, Ribeyre C, Yang Y, Zheng H, Damay P, Wang F, Tsujii $H$ et al (2011) A conserved motif within RAP1 has diversified roles in telomere protection and regulation in different organisms. Nat Struct Mol Biol 18:213-221

Chen LY, Zhang Y, Zhang Q, Li H, Luo Z, Fang H, Kim SH, Qin L, Yotnda P, Xu J et al (2012) Mitochondrial localization of telomeric protein TIN2 links telomere regulation to metabolic control. Mol Cell 47:839-850

Chen H, Liu X, Zhu W, Chen H, Hu X, Jiang Z, Xu Y, Wang L, Zhou Y, Chen $P$ et al (2014) SIRT1 ameliorates age-related senescence of mesenchymal stem cells via modulating telomere shelterin. Front Aging Neurosci 6:103

Chiang YJ, Kim SH, Tessarollo L, Campisi J, Hodes RJ (2004) Telomere-associated protein TIN2 is essential for early embryonic development through a telomerase-independent pathway. Mol Cell Biol 24:6631-6634

Churikov D, Wei C, Price CM (2006) Vertebrate POT1 restricts G-overhang length and prevents activation of a telomeric DNA damage checkpoint but is dispensable for overhang protection. Mol Cell Biol 26:6971-6982

Cohen SB, Graham ME, Lovrecz GO, Bache N, Robinson PJ, Reddel RR (2007) Protein composition of catalytically active human telomerase from immortal cells. Science 315:1850-1853

Court R, Chapman L, Fairall L, Rhodes D (2005) How the human telomeric proteins TRF1 and TRF2 recognize telomeric DNA: a view from high-resolution crystal structures. EMBO Rep 6:39-45

Dan J, Li M, Yang J, Li J, Okuka M, Ye X, Liu L (2013) Roles for Tbx3 in regulation of two-cell state and telomere elongation in mouse ES cells. Sci Rep 3:3492

Dan J, Yang J, Liu Y, Xiao A, Liu L (2015) Roles for histone acetylation in regulation of telomere elongation and two-cell state in mouse ES cells. J Cell Physiol 230:2337-2344

de Lange T (2018) Shelterin-mediated telomere protection. Annu Rev Genet 52:223-247

Denchi EL, de Lange T (2007) Protection of telomeres through independent control of ATM and ATR by TRF2 and POT1. Nature 448:1068-1071

Deng T, Huang Y, Weng K, Lin S, Li Y, Shi G, Chen Y, Huang J, Liu $\mathrm{D}, \mathrm{Ma} \mathrm{W}$ et al (2019) TOE1 acts as a 3' exonuclease for telomerase RNA and regulates telomere maintenance. Nucleic Acids Res 47:391-405

Doksani Y, Wu JY, de Lange T, Zhuang X (2013) Super-resolution fluorescence imaging of telomeres reveals TRF2-dependent T-loop formation. Cell 155:345-356

El Mai M, Wagner KD, Michiels JF, Ambrosetti D, Borderie A, Destree S, Renault V, Djerbi N, Giraud-Panis MJ, Gilson E et al (2014) The telomeric protein TRF2 regulates angiogenesis by binding and activating the PDGFRbeta promoter. Cell Rep 9:1047-1060

Falco G, Lee SL, Stanghellini I, Bassey UC, Hamatani T, Ko MS (2007) Zscan4: a novel gene expressed exclusively in late 2-cell embryos and embryonic stem cells. Dev Biol 307:539-550

Grammatikakis I, Zhang P, Panda AC, Kim J, Maudsley S, Abdelmohsen K, Yang X, Martindale JL, Motino O, Hutchison ER et al (2016) Alternative splicing of neuronal differentiation factor TRF2 regulated by HNRNPH1/H2. Cell Rep 15:926-934

Greider CW, Blackburn EH (1989) A telomeric sequence in the RNA of Tetrahymena telomerase required for telomere repeat synthesis. Nature 337:331-337

Griffith JD, Comeau L, Rosenfield S, Stansel RM, Bianchi A, Moss $H$, de Lange $T$ (1999) Mammalian telomeres end in a large duplex loop. Cell 97:503-514

Guo X, Deng Y, Lin Y, Cosme-Blanco W, Chan S, He H, Yuan G, Brown EJ, Chang S (2007) Dysfunctional telomeres activate an ATM-ATR-dependent DNA damage response to suppress tumorigenesis. Embo J 26:4709-4719

Han J, Yuan P, Yang H, Zhang J, Soh BS, Li P, Lim SL, Cao S, Tay J, Orlov YL et al (2010) Tbx3 improves the germ-line competency of induced pluripotent stem cells. Nature 463:1096-1100

He Q, Kim H, Huang R, Lu W, Tang M, Shi F, Yang D, Zhang X, Huang J, Liu D et al (2015) The Daxx/Atrx complex protects tandem repetitive elements during DNA hypomethylation by promoting H3K9 trimethylation. Cell Stem Cell 17:273-286

Herrera E, Samper E, Martin-Caballero J, Flores JM, Lee HW, Blasco MA (1999) Disease states associated with telomerase deficiency appear earlier in mice with short telomeres. EMBO J 18:2950-2960

Hirata T, Amano T, Nakatake Y, Amano M, Piao Y, Hoang HG, Ko MS (2012) Zscan4 transiently reactivates early embryonic genes during the generation of induced pluripotent stem cells. Sci Rep 2:208

Hockemeyer D, Daniels JP, Takai H, de Lange T (2006) Recent expansion of the telomeric complex in rodents: two distinct POT1 proteins protect mouse telomeres. Cell 126:63-77

Hoffmeyer K, Raggioli A, Rudloff S, Anton R, Hierholzer A, Del Valle I, Hein K, Vogt R, Kemler R (2012) Wnt/beta-catenin signaling regulates telomerase in stem cells and cancer cells. Science 336:1549-1554

Hosokawa K, MacArthur BD, Ikushima YM, Toyama H, Masuhiro Y, Hanazawa S, Suda T, Arai F (2017) The telomere binding protein Pot1 maintains haematopoietic stem cell activity with age. Nat Commun 8:804

Houghtaling BR, Cuttonaro L, Chang W, Smith S (2004) A dynamic molecular link between the telomere length regulator TRF1 and the chromosome end protector TRF2. Curr Biol 14:1621-1631

Huang J, Wang F, Okuka M, Liu N, Ji G, Ye X, Zuo B, Li M, Liang P, Ge WW et al (2011) Association of telomere length with authentic pluripotency of ES/iPS cells. Cell Res 21:779-792

Huang Y, Liang P, Liu D, Huang J, Songyang Z (2014) Telomere regulation in pluripotent stem cells. Protein Cell 5:194-202

Ikeda H, Sone M, Yamanaka S, Yamamoto T (2017) Structural and spatial chromatin features at developmental gene loci in human pluripotent stem cells. Nat Commun 8:1616 
Jaskelioff M, Muller FL, Paik JH, Thomas E, Jiang S, Adams AC, Sahin E, Kost-Alimova M, Protopopov A, Cadinanos J et al (2011) Telomerase reactivation reverses tissue degeneration in aged telomerase-deficient mice. Nature 469:102-106

Jiang J, Lv W, Ye X, Wang L, Zhang M, Yang H, Okuka M, Zhou C, Zhang X, Liu L et al (2013) Zscan4 promotes genomic stability during reprogramming and dramatically improves the quality of iPS cells as demonstrated by tetraploid complementation. Cell Res 23:92-106

Keegan CE, Hutz JE, Else T, Adamska M, Shah SP, Kent AE, Howes JM, Beamer WG, Hammer GD (2005) Urogenital and caudal dysgenesis in adrenocortical dysplasia (acd) mice is caused by a splicing mutation in a novel telomeric regulator. Hum Mol Genet 14:113-123

Kim SH, Kaminker P, Campisi J (1999) TIN2, a new regulator of telomere length in human cells. Nat Genet 23:405-412

Kim H, Lee OH, Xin H, Chen LY, Qin J, Chae HK, Lin SY, Safari A, Liu D, Songyang $Z$ (2009) TRF2 functions as a protein hub and regulates telomere maintenance by recognizing specific peptide motifs. Nat Struct Mol Biol 16:372-379

Kim H, Li F, He Q, Deng T, Xu J, Jin F, Coarfa C, Putluri N, Liu D, Songyang $Z$ (2017) Systematic analysis of human telomeric dysfunction using inducible telosome/shelterin CRISPR/Cas9 knockout cells. Cell Discov 3:17034

Kobayashi H, Kikyo N (2015) Epigenetic regulation of open chromatin in pluripotent stem cells. Transl Res 165:18-27

Lewis PW, Elsaesser SJ, Noh KM, Stadler SC, Allis CD (2010) Daxx is an H3.3-specific histone chaperone and cooperates with ATRX in replication-independent chromatin assembly at telomeres. Proc Natl Acad Sci USA 107:14075-14080

Li B, Oestreich S, de Lange T (2000) Identification of human Rap1: implications for telomere evolution. Cell 101:471-483

Lingner J, Hughes TR, Shevchenko A, Mann M, Lundblad V, Cech TR (1997) Reverse transcriptase motifs in the catalytic subunit of telomerase. Science 276:561-567

Liu L (2017) Linking telomere regulation to stem cell pluripotency. Trends Genet 33:16-33

Liu D, O'Connor MS, Qin J, Songyang Z (2004a) Telosome, a mammalian telomere-associated complex formed by multiple telomeric proteins. J Biol Chem 279:51338-51342

Liu D, Safari A, O'Connor MS, Chan DW, Laegeler A, Qin J, Songyang Z (2004b) PTOP interacts with POT1 and regulates its localization to telomeres. Nat Cell Biol 6:673-680

Liu L, Bailey SM, Okuka M, Munoz P, Li C, Zhou L, Wu C, Czerwiec E, Sandler L, Seyfang A et al (2007) Telomere lengthening early in development. Nat Cell Biol 9:1436-1441

Liu CC, Ma DL, Yan TD, Fan X, Poon Z, Poon LF, Goh SA, Rozen SG, Hwang WY, Tergaonkar $V$ et al (2016) Distinct responses of stem cells to telomere uncapping - a potential strategy to improve the safety of cell therapy. Stem Cells 34:2471-2484

Lobanova A, She R, Pieraut S, Clapp C, Maximov A, Denchi EL (2017) Different requirements of functional telomeres in neural stem cells and terminally differentiated neurons. Genes Dev 31:639-647

Lu R, Yang A, Jin Y (2011) Dual functions of T-box 3 (Tbx3) in the control of self-renewal and extraembryonic endoderm differentiation in mouse embryonic stem cells. J Biol Chem 286:8425-8436

Lu F, Liu Y, Jiang L, Yamaguchi S, Zhang Y (2014) Role of Tet proteins in enhancer activity and telomere elongation. Genes Dev 28:2103-2119

Marion RM, Strati K, Li H, Tejera A, Schoeftner S, Ortega S, Serrano M, Blasco MA (2009) Telomeres acquire embryonic stem cell characteristics in induced pluripotent stem cells. Cell Stem Cell 4:141-154

Marion RM, Lopez de Silanes I, Mosteiro L, Gamache B, Abad M, Guerra C, Megias D, Serrano M, Blasco MA (2017) Common telomere changes during in vivo reprogramming and early stages of tumorigenesis. Stem Cell Rep 8:460-475

Martinez P, Thanasoula M, Carlos AR, Gomez-Lopez G, Tejera AM, Schoeftner S, Dominguez O, Pisano DG, Tarsounas M, Blasco MA (2010) Mammalian Rap1 controls telomere function and gene expression through binding to telomeric and extratelomeric sites. Nat Cell Biol 12:768-780

Martinez P, Gomez-Lopez G, Garcia F, Mercken E, Mitchell S, Flores JM, de Cabo R, Blasco MA (2013) RAP1 protects from obesity through its extratelomeric role regulating gene expression. Cell Rep 3:2059-2074

Mendez-Bermudez A, Lototska L, Bauwens S, Giraud-Panis MJ, Croce O, Jamet K, Irizar A, Mowinckel M, Koundrioukoff S, Nottet $\mathrm{N}$ et al (2018) Genome-wide control of heterochromatin replication by the telomere capping protein TRF2. Mol Cell 70:449-461. e445

Meshorer E, Misteli T (2006) Chromatin in pluripotent embryonic stem cells and differentiation. Nat Rev Mol Cell Biol 7:540-546

Nakashima M, Nandakumar J, Sullivan KD, Espinosa JM, Cech TR (2013) Inhibition of telomerase recruitment and cancer cell death. J Biol Chem 288:33171-33180

Nandakumar J, Bell CF, Weidenfeld I, Zaug AJ, Leinwand LA, Cech TR (2012) The TEL patch of telomere protein TPP1 mediates telomerase recruitment and processivity. Nature 492:285-289

Niida H, Shinkai Y, Hande MP, Matsumoto T, Takehara S, Tachibana M, Oshimura M, Lansdorp PM, Furuichi Y (2000) Telomere maintenance in telomerase-deficient mouse embryonic stem cells: characterization of an amplified telomeric DNA. Mol Cell Biol 20:4115-4127

O'Connor MS, Safari A, Liu D, Qin J, Songyang Z (2004) The human Rap1 protein complex and modulation of telomere length. J Biol Chem 279:28585-28591

O'Connor MS, Safari A, Xin H, Liu D, Songyang Z (2006) A critical role for TPP1 and TIN2 interaction in high-order telomeric complex assembly. Proc Natl Acad Sci USA 103:11874-11879

Orun O, Tiber PM, Serakinci N (2016) Partial knockdown of TRF2 increase radiosensitivity of human mesenchymal stem cells. Int $\mathrm{J}$ Biol Macromol 90:53-58

Ovando-Roche P, Yu JS, Testori S, Ho C, Cui W (2014) TRF2mediated stabilization of hREST4 is critical for the differentiation and maintenance of neural progenitors. Stem Cells 32:21112122

Pfaff N, Lachmann N, Ackermann M, Kohlscheen S, Brendel C, Maetzig T, Niemann H, Antoniou MN, Grez M, Schambach A et al (2013) A ubiquitous chromatin opening element prevents 
transgene silencing in pluripotent stem cells and their differentiated progeny. Stem Cells 31:488-499

Pucci F, Gardano L, Harrington L (2013) Short telomeres in ESCs lead to unstable differentiation. Cell Stem Cell 12:479-486

Rai R, Chen Y, Lei M, Chang S (2016) TRF2-RAP1 is required to protect telomeres from engaging in homologous recombinationmediated deletions and fusions. Nat Commun 7:10881

Rivera T, Haggblom C, Cosconati S, Karlseder J (2017) A balance between elongation and trimming regulates telomere stability in stem cells. Nat Struct Mol Biol 24:30-39

Rudolph KL, Chang S, Lee HW, Blasco M, Gottlieb GJ, Greider C, DePinho RA (1999) Longevity, stress response, and cancer in aging telomerase-deficient mice. Cell 96:701-712

Santos J, Pereira CF, Di-Gregorio A, Spruce T, Alder O, Rodriguez T, Azuara V, Merkenschlager M, Fisher AG (2010) Differences in the epigenetic and reprogramming properties of pluripotent and extra-embryonic stem cells implicate chromatin remodelling as an important early event in the developing mouse embryo. Epigenet Chromatin 3:1

Schneider RP, Garrobo I, Foronda M, Palacios JA, Marion RM, Flores I, Ortega S, Blasco MA (2013) TRF1 is a stem cell marker and is essential for the generation of induced pluripotent stem cells. Nat Commun 4:1946

Serakinci N, Mega Tiber P, Orun O (2018) Chromatin modifications of hTERT gene in hTERT-immortalized human mesenchymal stem cells upon exposure to radiation. Eur J Med Genet 61:288293

Sexton AN, Youmans DT, Collins K (2012) Specificity requirements for human telomere protein interaction with telomerase holoenzyme. J Biol Chem 287:34455-34464

Sexton AN, Regalado SG, Lai CS, Cost GJ, O'Neil CM, Urnov FD, Gregory PD, Jaenisch R, Collins K, Hockemeyer D (2014) Genetic and molecular identification of three human TPP1 functions in telomerase action: recruitment, activation, and homeostasis set point regulation. Genes Dev 28:1885-1899

Sfeir A, Kosiyatrakul ST, Hockemeyer D, MacRae SL, Karlseder J, Schildkraut CL, de Lange T (2009) Mammalian telomeres resemble fragile sites and require TRF1 for efficient replication. Cell 138:90-103

Sfeir A, Kabir S, van Overbeek M, Celli GB, de Lange T (2010) Loss of Rap1 induces telomere recombination in the absence of NHEJ or a DNA damage signal. Science 327:1657-1661

Stansel RM, de Lange T, Griffith JD (2001) T-loop assembly in vitro involves binding of TRF2 near the 3' telomeric overhang. Embo J 20:5532-5540

Stout GJ, Blasco MA (2009) Genetic dissection of the mechanisms underlying telomere-associated diseases: impact of the TRF2 telomeric protein on mouse epidermal stem cells. Dis Model Mech 2:139-156

Takai KK, Kibe T, Donigian JR, Frescas D, de Lange T (2011) Telomere protection by TPP1/POT1 requires tethering to TIN2. Mol Cell 44:647-659

Tejera AM, Stagno d'Alcontres M, Thanasoula M, Marion RM, Martinez P, Liao C, Flores JM, Tarsounas M, Blasco MA (2010) TPP1 is required for TERT recruitment, telomere elongation during nuclear reprogramming, and normal skin development in mice. Dev Cell 18:775-789
Teo H, Ghosh S, Luesch H, Ghosh A, Wong ET, Malik N, Orth A, de Jesus P, Perry AS, Oliver JD et al (2010) Telomere-independent Rap1 is an IKK adaptor and regulates NF-kappaB-dependent gene expression. Nat Cell Biol 12:758-767

van Steensel B, de Lange T (1997) Control of telomere length by the human telomeric protein TRF1. Nature 385:740-743

van Steensel B, Smogorzewska A, de Lange T (1998) TRF2 protects human telomeres from end-to-end fusions. Cell 92:401413

Varela E, Schneider RP, Ortega S, Blasco MA (2011) Different telomere-length dynamics at the inner cell mass versus established embryonic stem (ES) cells. Proc Natl Acad Sci USA 108:15207-15212

Wang Y, Erdmann N, Giannone RJ, Wu J, Gomez M, Liu Y (2005) An increase in telomere sister chromatid exchange in murine embryonic stem cells possessing critically shortened telomeres. Proc Natl Acad Sci USA 102:10256-10260

Wang F, Podell ER, Zaug AJ, Yang Y, Baciu P, Cech TR, Lei M (2007) The POT1-TPP1 telomere complex is a telomerase processivity factor. Nature 445:506-510

Wang Y, Shen MF, Chang S (2011) Essential roles for Pot1b in HSC self-renewal and survival. Blood 118:6068-6077

Wang F, Yin Y, Ye X, Liu K, Zhu H, Wang L, Chiourea M, Okuka M, Ji G, Dan J et al (2012) Molecular insights into the heterogeneity of telomere reprogramming in induced pluripotent stem cells. Cell Res 22:757-768

Wang H, Zhang K, Liu Y, Fu Y, Gao S, Gong P, Wang H, Zhou Z, Zeng $M, W u Z$ et al (2017) Telomere heterogeneity linked to metabolism and pluripotency state revealed by simultaneous analysis of telomere length and RNA-seq in the same human embryonic stem cell. BMC Biol 15:114

Wong LH, Ren H, Williams E, McGhie J, Ahn S, Sim M, Tam A, Earle E, Anderson MA, Mann J et al (2009) Histone H3.3 incorporation provides a unique and functionally essential telomeric chromatin in embryonic stem cells. Genome Res 19:404-414

Wong CW, Hou PS, Tseng SF, Chien CL, Wu KJ, Chen HF, Ho HN, Kyo S, Teng SC (2010a) Kruppel-like transcription factor 4 contributes to maintenance of telomerase activity in stem cells. Stem Cells 28:1510-1517

Wong LH, McGhie JD, Sim M, Anderson MA, Ahn S, Hannan RD, George AJ, Morgan KA, Mann JR, Choo KH (2010b) ATRX interacts with $\mathrm{H} 3.3$ in maintaining telomere structural integrity in pluripotent embryonic stem cells. Genome Res 20:351-360

Xin $H$, Liu D, Wan $M$, Safari A, Kim H, Sun W, O'Connor MS, Songyang Z (2007) TPP1 is a homologue of ciliate TEBP-beta and interacts with POT1 to recruit telomerase. Nature 445:559562

Xin H, Liu D, Songyang Z (2008) The telosome/shelterin complex and its functions. Genome Biol 9:232

Yang C, Przyborski S, Cooke MJ, Zhang X, Stewart R, Anyfantis G, Atkinson SP, Saretzki G, Armstrong L, Lako M (2008) A key role for telomerase reverse transcriptase unit in modulating human embryonic stem cell proliferation, cell cycle dynamics, and in vitro differentiation. Stem Cells 26:850-863

Yang D, He Q, Kim H, Ma W, Songyang Z (2011) TIN2 protein dyskeratosis congenita missense mutants are defective in association with telomerase. J Biol Chem 286:23022-23030 
Ye JZ, Donigian JR, van Overbeek M, Loayza D, Luo Y, Krutchinsky AN, Chait BT, de Lange T (2004a) TIN2 binds TRF1 and TRF2 simultaneously and stabilizes the TRF2 complex on telomeres. J Biol Chem 279:47264-47271

Ye JZ, Hockemeyer D, Krutchinsky AN, Loayza D, Hooper SM, Chait BT, de Lange T (2004b) POT1-interacting protein PIP1: a telomere length regulator that recruits POT1 to the TIN2/TRF1 complex. Genes Dev 18:1649-1654

Zalzman M, Falco G, Sharova LV, Nishiyama A, Thomas M, Lee SL, Stagg CA, Hoang HG, Yang HT, Indig FE et al (2010) Zscan4 regulates telomere elongation and genomic stability in ES cells. Nature 464:858-863

Zeng S, Liu L, Sun Y, Xie P, Hu L, Yuan D, Chen D, Ouyang Q, Lin G, Lu G (2014) Telomerase-mediated telomere elongation from human blastocysts to embryonic stem cells. J Cell Sci 127:752762
Zhang P, Pazin MJ, Schwartz CM, Becker KG, Wersto RP, Dilley CM, Mattson MP (2008) Nontelomeric TRF2-REST interaction modulates neuronal gene silencing and fate of tumor and stem cells. Curr Biol 18:1489-1494

Zhang P, Abdelmohsen K, Liu Y, Tominaga-Yamanaka K, Yoon JH, loannis G, Martindale JL, Zhang Y, Becker KG, Yang IH et al (2015a) Novel RNA- and FMRP-binding protein TRF2-S regulates axonal mRNA transport and presynaptic plasticity. Nat Commun 6:8888

Zhang Y, Chiu S, Liang X, Gao F, Zhang Z, Liao S, Liang Y, Chai YH, Low DJ, Tse HF et al (2015b) Rap1-mediated nuclear factorkappaB (NF-kappaB) activity regulates the paracrine capacity of mesenchymal stem cells in heart repair following infarction. Cell Death Discov 1:15007

Zhong FL, Batista LF, Freund A, Pech MF, Venteicher AS, Artandi SE (2012) TPP1 OB-fold domain controls telomere maintenance by recruiting telomerase to chromosome ends. Cell 150:481-494 